\title{
Rancang Bangun Trash Skimmer Boat Sebagai Salah Satu Solusi Alternatif Pengambilan Sampah di Sungai Indonesia
}

\section{Design and Build a Trash Skimmer Boat as a Solution For Collecting Trash in Indonesian Rivers}

\author{
Muhammad Rafi ${ }^{1 *}$, Rizal Hanifi ${ }^{2}$, Deri Teguh Santoso ${ }^{3}$ \\ 1,2,3 Program Studi Teknik Mesin, Fakultas Teknik, Universitas Singaperbangsa Karawang, \\ Indonesia
}

Diterima: 01-11-2020 ; Disetujui: 17-02-2021 ; Diterbitkan: 06-05-2021

*Corresponding author: E-mail: muhammadrafi12936@gmail.com

\begin{abstract}
Abstrak
Trash Skimmer Boat merupakan salah satu jenis dari kapal khusus dimana kapal ini di fungsikan untuk melakukan pengambilan sampah perairan baik perairan sungai, danau, laut maupun kanal. Metode perancangan Trash Skimmer Boat ini meliputi: perancangan desain, perancangan elemen mesin, menentukan komponen-komponen elektrikal, menentukan biaya pembuatan serta nantinya akan di uji coba guna mendapatkan kapasitas aktual yang bisa didapatkan. Dari hasil perancangan yang dibuat didapatkan spesifikasi kemiringan rantai $45^{\circ}$, panjang $100 \mathrm{~cm}$, lebar $40 \mathrm{~cm}$, tinggi $50 \mathrm{~cm}$ dan jumlah bucket sebanyak lima. Trash Skimmer Boat ini membutuhkan kecepatan sebesar $0.46 \mathrm{~m} / \mathrm{s}$ untuk mencapai kapasitas yang ditargetkan yaitu sebesar $5 \mathrm{~kg} / \mathrm{jam}$. Untuk komponen elemen mesin yang digunakan pada Trash Skimmer Boat ini yaitu poros berdiameter $12 \mathrm{~mm}$, bearing dengan diameter bore $12 \mathrm{~mm}$, rantai RS 35 dan sprocket RS 35-1B 20 T. Daya yang dibutuhkan untuk menggerakkan conveyor pada Trash Skimmer Boat ini adalah sebesar 40 watt dan sumber daya yang dihasilkan berasal dari aki $12 \mathrm{~V} 4 \mathrm{AH}$ dan motor penggerak conveyor yang digunakan adalah motor DC 12V 50 RPM. Biaya yang dibutuhkan untuk membuat Trash Skimmer Boat ini adalah Rp 1.787.000,-. Kapasitas aktual yang berhasil didapatkan oleh Trash Skimmer Boat ini adalah sebesar 200-300 gram dengan pengoperasian selama 30 menit.
\end{abstract}

Kata Kunci: kapasitas; sampah; trash skimmer boat,

\begin{abstract}
Trash Skimmer Boat is one type of special ship where the ship is functioned to perform retrieval of wastewaters fine the waters of the river, lake, sea, or canal. Methods design of the Trash Skimmer Boat includes: the engineering design, determine of machine elements, determining the components of electrical components, determine the cost of manufacture, and will be in trials in order to get the actual capacity that can be obtained.From the results of the design that made the specification obtained the slope of the chain $45^{\circ}$, length $100 \mathrm{~cm}$, width $40 \mathrm{~cm}$, height $50 \mathrm{~cm}$, and the number of buckets as much as five. Trash Skimmer Boat requires a speed of $0.46 \mathrm{~m} / \mathrm{s}$ to achieve the capacity that is targeted by $5 \mathrm{~kg} / \mathrm{h}$. For the component elements of the machine that is used on the Trash Skimmer Boat is the shaft diameter $12 \mathrm{~mm}$, bearings with a bore diameter of $12 \mathrm{~mm}$, chain is RS 35, and the sprocket RS 35-1B $20 \mathrm{~T}$. The power needed to move the conveyor in the Trash Skimmer Boat is equal to 40 watts and a source power that is produced comes from the battery $12 \mathrm{~V} 4 \mathrm{AH}$ and a motor of conveyor used is a DC motor $12 \mathrm{~V} 50 \mathrm{RPM}$. The cost needed to make a Trash Skimmer Boat this is a Rp 1.787.000,-. The actual capacity that is achieved by the Trash Skimmer Boat this amounted to 200-300 grams with the operation for 30 minutes.
\end{abstract}

Keywords: capacity; garbage; trash skimmer boat

How to Cite: Rafi, M., 2021, Rancang Bangun Trash Skimmer Boat sebagai Salah Satu Solusi Alternatif Pengambilan Sampah di Sungai Indonesia, JMEMME (Journal of Mechanical Engineering, Manufactures, Materials and Energy), 5 (1): 57-68 
Rafi, Muhammad, Rancang Bangun Trash Skimmer Boat sebagai Salah Satu Solusi.....

\section{PENDAHULUAN}

Indonesia diperkirakan menghasilkan 64 juta ton sampah setiap tahun. Berdasarkan data Kementerian Lingkungan Hidup dan Kehutanan (KLHK), komposisi sampah didominasi oleh sampah organik, yakni mencapai 60\% dari total sampah. Sampah plastik menempati posisi kedua dengan 14\% disusul sampah kertas 9\% dan karet 5,5\%. Sampah lainnya terdiri atas logam, kain, kaca, dan jenis sampah lainnya [1]. Lebih lanjut, pertambahan jumlah penduduk, perubahan pola konsumsi, dan gaya hidup masyarakat telah meningkatkan jumlah timbunan sampah, jenis, dan keberagaman karakteristik sampah. Meningkatnya volume timbulan sampah memerlukan pengelolaan yang baik termasuk dalam pemindahan sampah [2].

Sejauh ini, pemindahan sampah dari sungai dilakukan di pintu air dengan menggunakan eskavator dan krane maupun secara manual menggunakan pelampung di pinggiran sungai. Pemindahan sampah menggunakan alat tersebut tentunya akan memerlukan banyak tenaga manusia (operator). Sehingga kemampuan serta jam kerja dari pemindahan sampah ini menjadi terbatas. Akibatnya ketika air membawa sampah dalam jumlah banyak, metode yang ada tidak akan mampu mengakomodir pemindahan. sehingga sampah akan menumpuk dan pintu air akan tersumbat. Maka perlu adanya metode baru yang dapat mengatasi permasalahan tersebut, yaitu dengan pengangkatan secara bertahap tanpa melibatkan operator atau dengan kata lain hanya dengan melibatkan operator seminimum mungkin [3].

Salah satu solusi dari permasalahan yang dapat digunakan untuk mengatasi penumpukan sampah yang ada disungai yaitu dengan menggunakan bantuan Trash Skimmer Boat. Trash Skimmer Boat adalah salah satu jenis dari kapal khusus dimana kapal ini di fungsikan untuk melakukan pengambilan sampah perairan baik perairan sungai, danau, laut maupun kanal. Bentuk dasar dari Trash Skimmer Boat ini adalah berlambung katamaran. Kapal ini juga dilengkapi dengan bak sampah yang dimana berfungsi sebagai bak penampung untuk mengumpulkan sampah dari perairan [4].

Adapun sebagai bahan referensi yang telah ada adalah sebagai berikut: Desain Trash Skimmer Amphibi-Boat di Sungai Ciliwung Jakarta (gambar 1) [5], Studi perancangan Trash-Skimmer Boat di perairan teluk Jakarta (gambar 2) [6], dan Desain Aquatic Weed and Trash Skimmer Boat dengan sistem penggerak Paddle Wheel di Sungai Kalimas Surabaya (gambar 3) [7, 8]. 

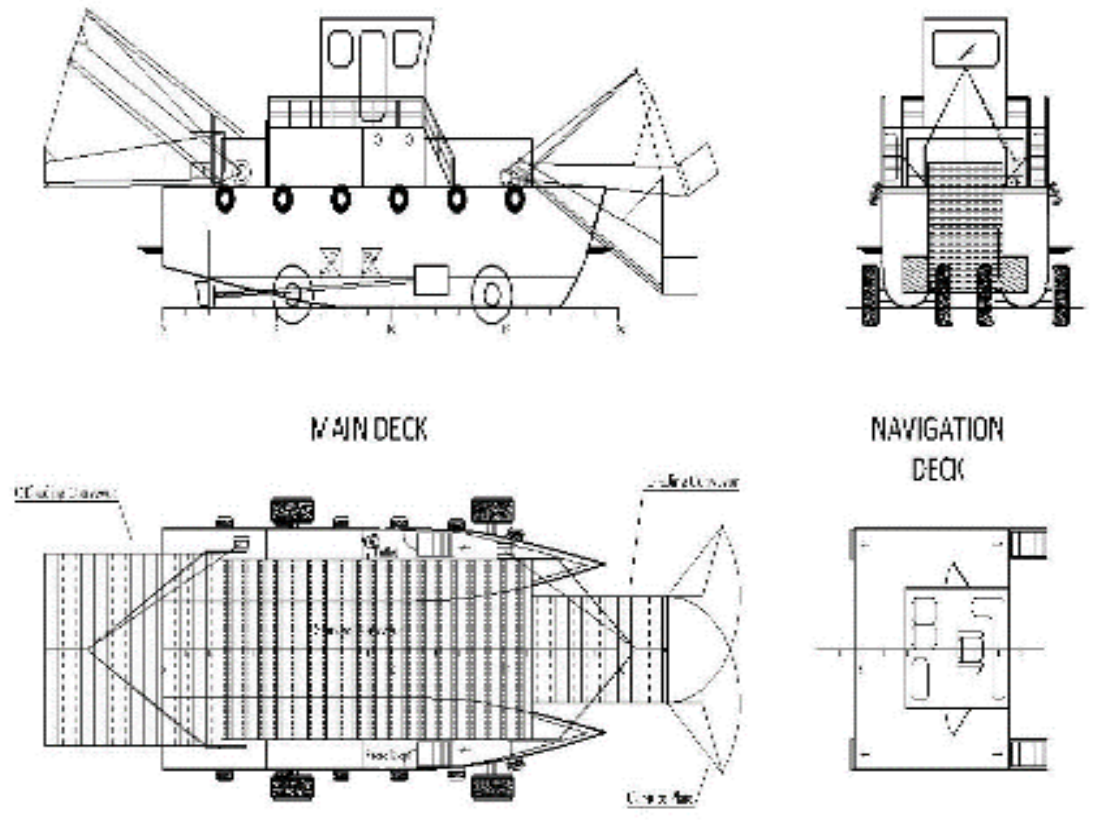

NAVIGATION

CEOC:

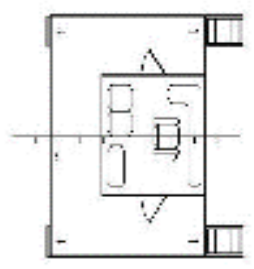

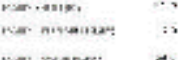

ner. wanes:

and

Gambar 1. Desain Trash Skimmer Amphibi-boat

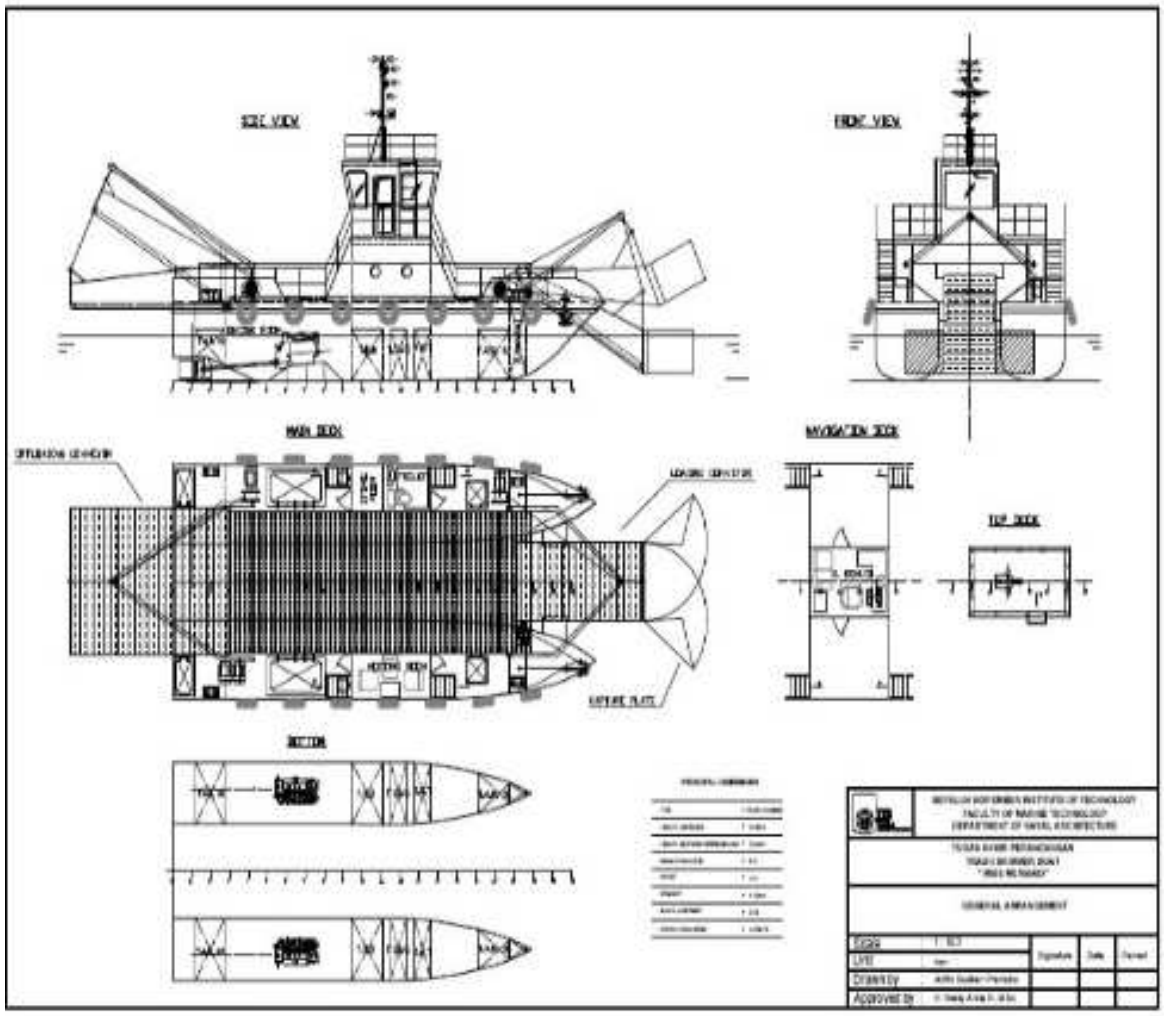

Gambar 2. Desain Trash-Skimmer Boat di perairan teluk Jakarta 


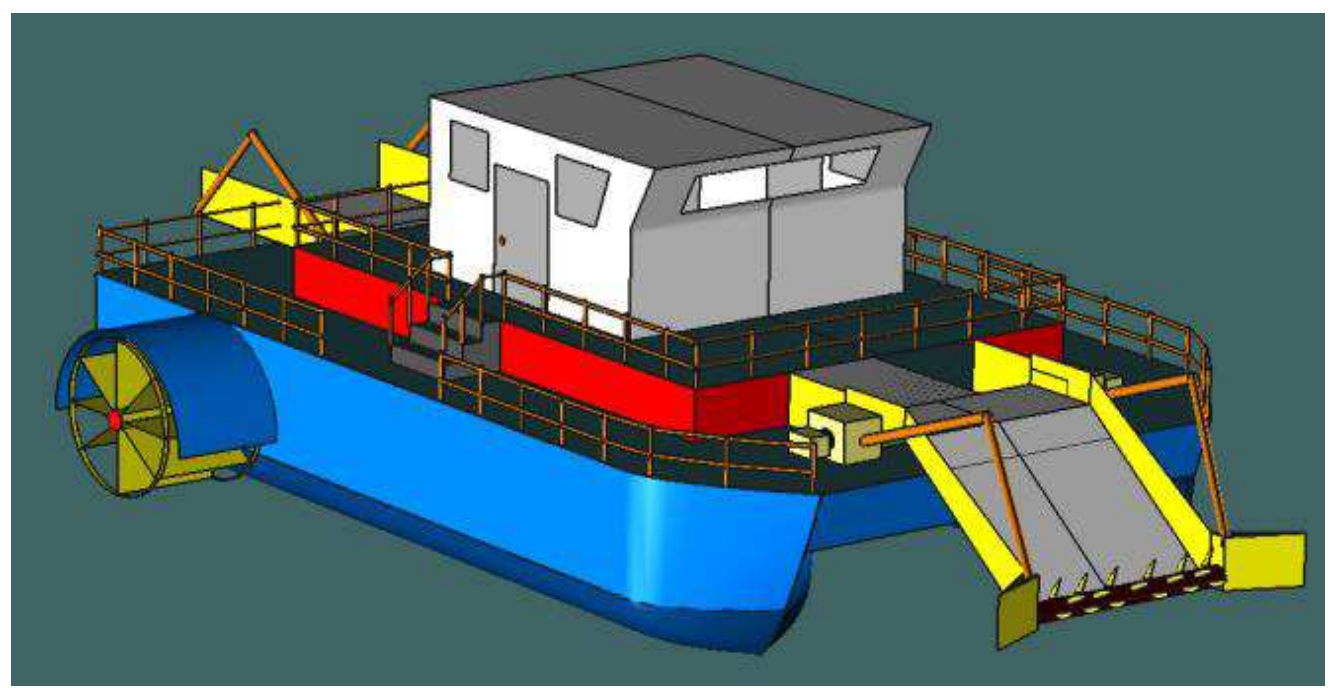

Gambar 3. Desain Aquatic Weedand Trash Skimmer Boat

Adapun tujuan penelitian ialah: untuk merancang purwarupa Trash Skimmer Boat, untuk mendapatkan ukuran utama dari Trash Skimmer Boat yang handal dalam pembersihan sampah di sungai, mengetahui faktor-faktor yang berhubungan dengan rancang bangun Trash Skimmer Boat (kecepatan pemindahan, ukuran komponenkomponen yang digunakan serta daya yang dibutuhkan), dan mengetahui kapasitas aktual yang berhasil didapatkan.

Dan rumus-rumus dan teori yang penulis gunakan dalam penelitian ini antara lain sebagai berikut: untuk merancang alat ini penulis menggunakan teori Roadmap to Engineering Design [9], untuk mencari kecepatan pemindahan yang dibutuhkan menggunakan persamaan 1 [10, 11], untuk mencari rantai yang dibutuhkan menggunakan persamaan $2[12,13]$, untuk mencari daya yang dibutuhkan menggunakan persamaan 3, untuk mencari poros yang digunakan menggunakan dua teori yaitu teori guest dan teori rankine $[14,15]$ melalui persamaan 4 dan 5.

$$
\begin{aligned}
Q & =\frac{C x F}{1000} x \frac{3600 v}{s} \times \frac{\rho}{1000} \\
P & =(M+W) x(f x c x \cos \alpha+c x \sin \alpha)+(f x \cos \alpha-\sin \alpha) \times W \times c \\
P & =T . \omega \\
d & =\sqrt[3]{\frac{16 x T e}{\pi x \tau}}
\end{aligned}
$$




$$
d=\sqrt[3]{\frac{32 x M e}{\pi x \sigma \mathrm{b}}}
$$

Trash Skimmer Boat yang penulis rancang bangun ini menawarkan suatu sistem pembersih sampah diatas aliran sungai menggunakan Remote Control yang dihubungkan melalui Wireless hal ini dilakukan untuk mengurangi volume serta bobot dari workboat itu sendiri dan juga memudahkan untuk menjangkau daerah-daerah anak sungai yang lebih kecil

\section{METODE PENELITIAN}

Alat yang digunakan pada tahap perancangan ini adalah perangkat laptop, dengan menggunakan software perancangan Autodesk Inventor Professional 2017 x64 Edition, jangka sorong yang digunakan untuk mengukur secara presisi komponen-komponen yang akan digunakan, meteran, dan kalkulator. Sementara itu tahapan-tahapan dalam rancang bangun Trash Skimmer Boat secara umum ditunjukkan pada gambar 4.

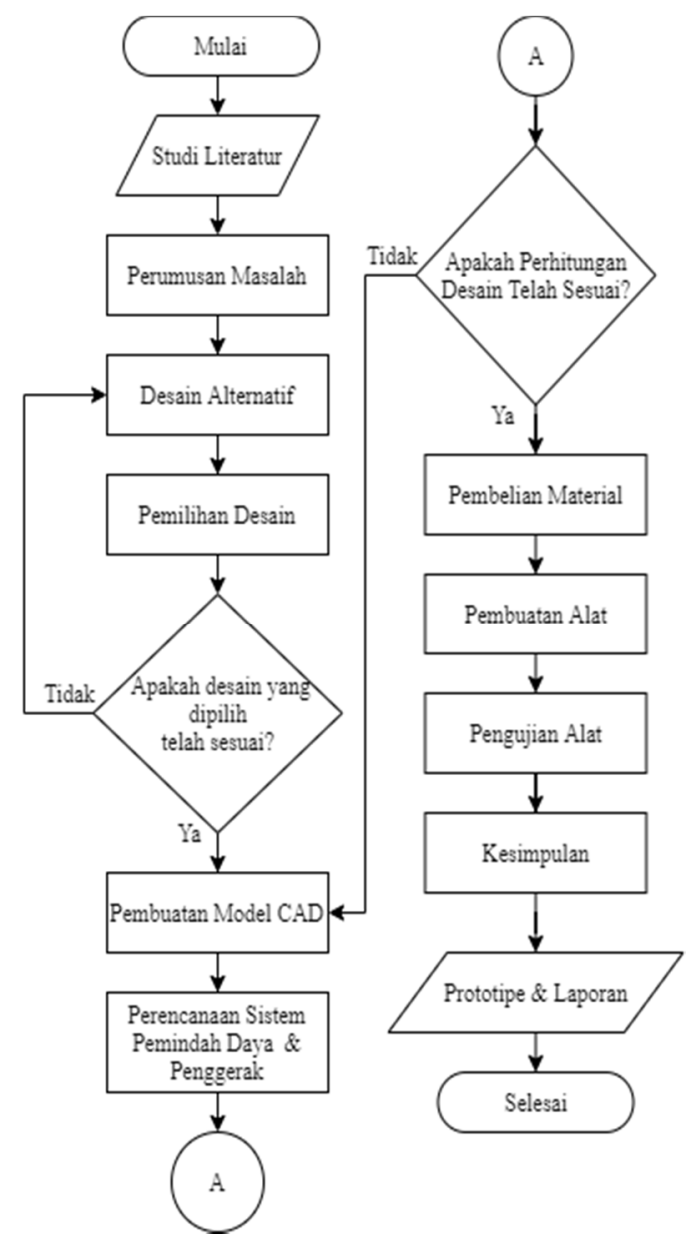

Gambar 4. Diagram alir perancangan trash skimmer boat 
Tahapan selanjutnya adalah mengenai sistem pemindah daya, dimana tahapan dalam perencanaan sistem tersebut diperlihatkan pada gambar 5 .

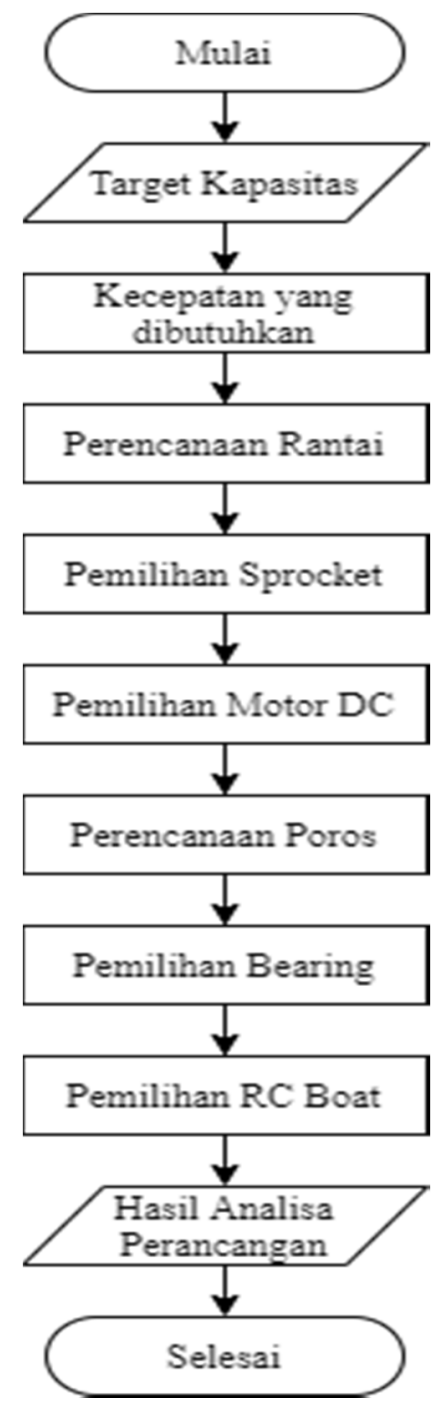

Gambar 5. Diagram alir untuk sistem pemindahan daya

Untuk mencari kecepatan yang dibutuhkan pada target kapasitas yang diinginkan maka dapat menggunakan rumus kapasitas bucket. Bucket digunakan untuk menampung benda yang akan dipindahkan.

Tahap selanjutnya adalah melakukan perencanaan rantai dimana rantai memiliki peran penting dalam menyalurkan tenaga dari motor DC ke komponen lainnya. Tahapan selanjutnya adalah pemilihan sprocket. Untuk pemilihan sprocket disesuaikan kembali dengan rantai yang telah di rencanakan dan melihat kondisi ketersediaan barang di pasaran. Setelah memilih sprocket yang akan digunakan maka kita dapat mengetahui berat sprocket melalui tabel katalog perusahaan penyedia sprocket tersebut serta 
panjang rantai. Setelah itu melakukan penghitungan untuk mengetahui daya yang dibutuhkan agar bisa menjalankan conveyor.

Sesuai dengan gambar 5, tahapan selanjutnya adalah melakukan perencanaan poros. Tujuan dari perencanaan poros ini adalah untuk menentukan ukuran diameter poros yang sesuai. Kemudian dilakukan pemilihan bearing, dimana untuk pemilihan bearing itu sendiri disesuaikan kembali dengan diameter poros yang telah di rencanakan dan melihat kondisi ketersediaan barang di pasaran.

Akhirnya, tahap selanjutnya adalah pemilihan RC Boat, disesuaikan dengan ketinggian permukaan air. Pengukuran ketinggian permukaan air ialah ketika alat tersebut berada di atas air sehingga nantinya bisa digunakan sebagai penggerak bagi alat tersebut.

\section{HASIL DAN PEMBAHASAN}

Perancangan dan pemilihan desain sesuai dengan roadmap to engineering design didapatkan hasil sketsa rancangan seperti diperlihatkan pada gambar 6. Selanjutkan dilakukan pembuatan model CAD untuk mengetahui bentuk dari rancangan yang akan dibuat secara 3D dengan menggunakan software Autodesk Inventor. Model CAD yang dikerjakan diperlihatkan pada gambar 7.

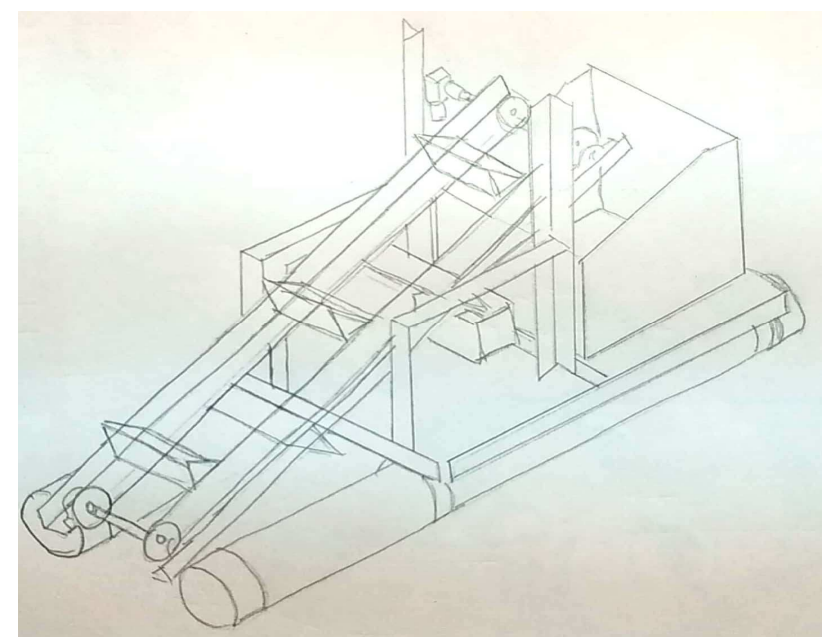

Gambar 6. Desain rancangan terpilih 


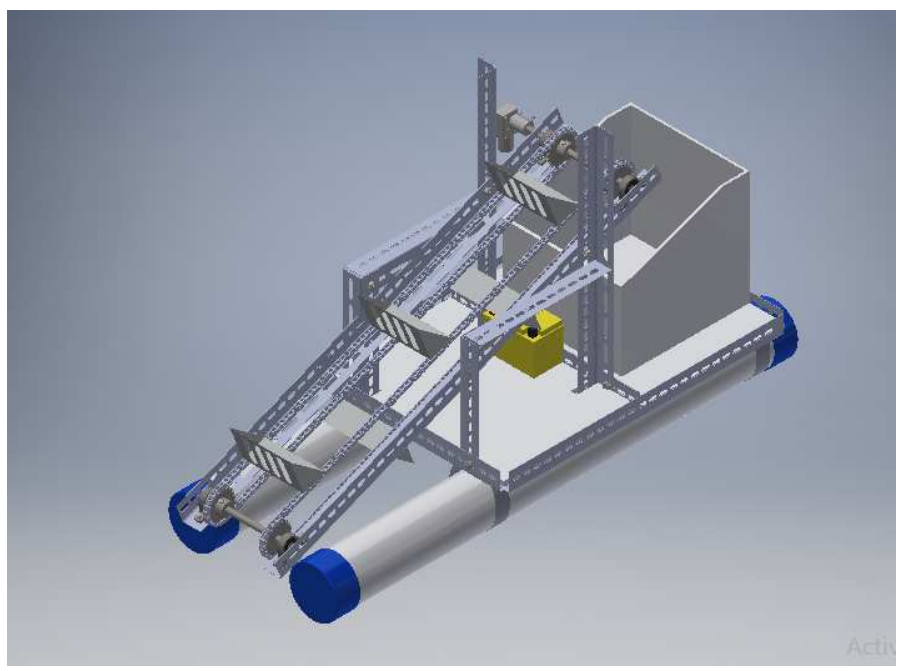

Gambar 7. Pembuatan model secara CAD

Tahapan selanjutnya adalah melakukan perencanaan kecepatan pemindahan yang dibutuhkan dengan menggunakan persamaan (1) didapatkan hasil sebesar $0.46 \mathrm{~m} / \mathrm{s}$. Setelah itu dilakukan penghitungan beban bucket dengan menggunakan persamaan (2) Hasil perhitungan dengan volume bucket (C) 0,06 liter dan massa jenis (p) $1000 \mathrm{~kg} / \mathrm{m}^{3}$ maka didapatkan massa beban bucket yaitu sebesar $0.6 \mathrm{~kg}$. Selanjutnya mencari beban total dengan mengkalikan massa beban bucket dengan jumlah bucket sehingga didapatkan massa total bucket kosong ditambah dengan isi adalah 2,1 kg.

Proses perancangan elemen-elemen mesin Trash Skimmer Boat dimulai dari perencanaan rantai dimana rantai yang dipilih adalah RS 35 yang terbukti dengan menggunakan rantai RS 35 bisa digunakan dengan acuan nilai yang dihasilkan masih dibawah nilai max. allowable load yang dapat diterima oleh rantai tersebut. Proses pemilihan sprocket didasarkan pada pemilihan rantai agar sesuai. Oleh karena itu, dipilih sprocket sementara dengan tipe serupa yaitu sprocket RS 35-1B 20 T. Perhitungan daya yang dibutuhkan ialah sekitar 7.3 watt dengan sumber daya yang akan digunakan adalah berasal dari aki 12V 4 AH dan untuk pemilihan motor DC yang akan digunakan sementara adalah motor DC gearbox 37012 volt $50 \mathrm{rpm}$. Pemilihan poros bertujuan untuk mendapatkan poros berdiameter $11.38 \mathrm{~mm} \approx 12 \mathrm{~mm}$ berdasarkan persamaan (5) dan ketersediaan barang dipasaran. Untuk bearing yang akan digunakan disesuaikan dengan besar diameter poros yang telah dipilih yaitu $12 \mathrm{~mm}$, maka dari itu dipilih bearing dengan besar lubang diameter sebesar 12 mm dengan kode KP001.

RC Boat sendiri akan dipilih tipe HJ8068 V FT009, dikarenakan memiliki kapasitas baterai terbesar yaitu $3000 \mathrm{mAH}$ dengan kecepatan $35 \mathrm{~km} / \mathrm{h}$. keunggulan lainnya RC 
Boat jenis ini yaitu low-voltage protection ketika tenaga baterai hampir habis. Lampu LED pada remote akan berkedip dan mengeluarkan suara peringatan, sehingga RC Boat bisa secepatnya dikontrol pulang ke pangkalan.

Setelah melakukan perancangan dan pembuatan, maka dihasilkan sebuah prototipe Trash Skimmer Boat dengan spesifikasi yang telah dikonsep sebelumnya dengan kemiringan rantai 45, panjang $100 \mathrm{~cm}$, lebar $40 \mathrm{~cm}$, tinggi $50 \mathrm{~cm}$ dan jumlah bucket sebanyak lima. Pembuatan alat ini memerlukan waktu selama 3 hari. Prototipe Trash Skimmer Boat ini dapat dilihat pada gambar 8. Proses pengujian kapasitas alat ini dilakukan sebanyak dua kali dengan hasil yang dapat dilihat pada tabel 1.

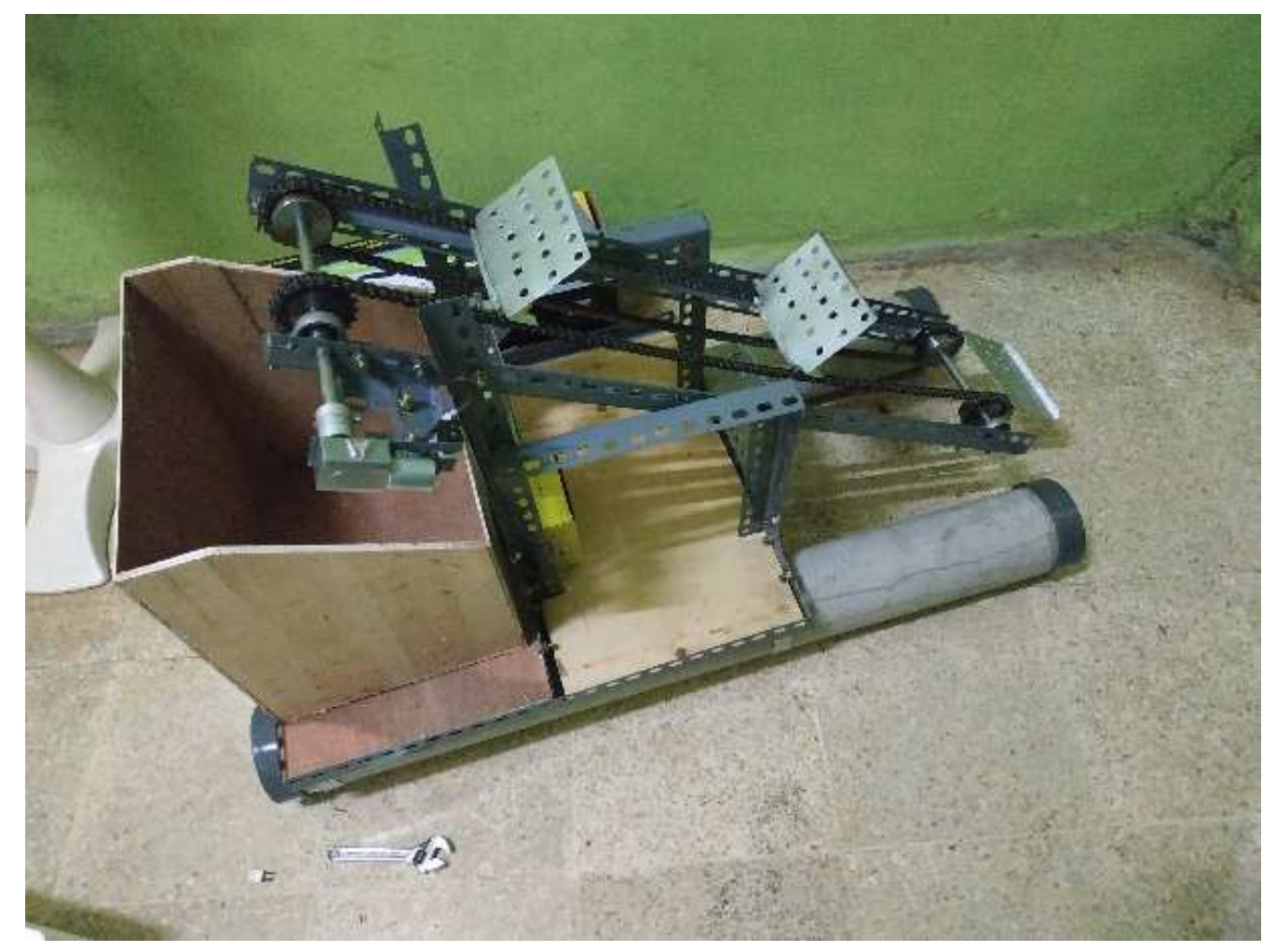

Gambar 8. Prototipe trash skimmer boat

Tabel 1. Hasil Uji Kinerja Alat

\begin{tabular}{cccc}
\hline $\begin{array}{c}\text { Pengujian } \\
\text { ke- }\end{array}$ & $\begin{array}{c}\text { Waktu Operasi } \\
\text { (menit) }\end{array}$ & Kapasitas Aktual (g) & $\begin{array}{c}\text { Kapasitas Target } \\
(\mathrm{kg} / \mathrm{jam})\end{array}$ \\
\hline 1 & 30 & 200 & 5 \\
2 & 30 & 300 & 5 \\
\hline
\end{tabular}


Berdasarkan hasil uji coba didapatkan bahwa alat dapat beroperasi selama 30 menit dengan kapasitas yang didapatkan sebanyak 200-300 gram dalam sekali pengoperasian. Hal ini dikarenakan kapasitas dari baterai RC Boat yang digunakan hanya dapat beroperasi selama 30 menit dan membutuhkan waktu charge selama 4 jam. Hal ini juga disebabkan oleh sulitnya pengambilan sampah yang ada, dimana ketika melakukan proses pengambilan sampah, sampah sudah terlebih dahulu terdorong oleh pergerakan dari bucket sehingga menyebabkan sampah tersebut menjauh. Dan untuk mendapatkan sampah tersebut memerlukan manuver yang cepat dari alat ini agar sampah tersebut dapat terangkut sehingga membutuhkan skill dalam pengoperasian alat. Selain itu juga disebabkan oleh menyangkutnya sampah plastik pada baling-baling RC Boat yang dapat menghambat pergerakan dari alat ini sehingga alat ini harus ditarik menggunakan tali ke pangkalan untuk melepaskan sampah plastik yang tersangkut pada baling-baling. Untuk hasil yang didapatkan dapat dilihat pada gambar 9 dan 10.

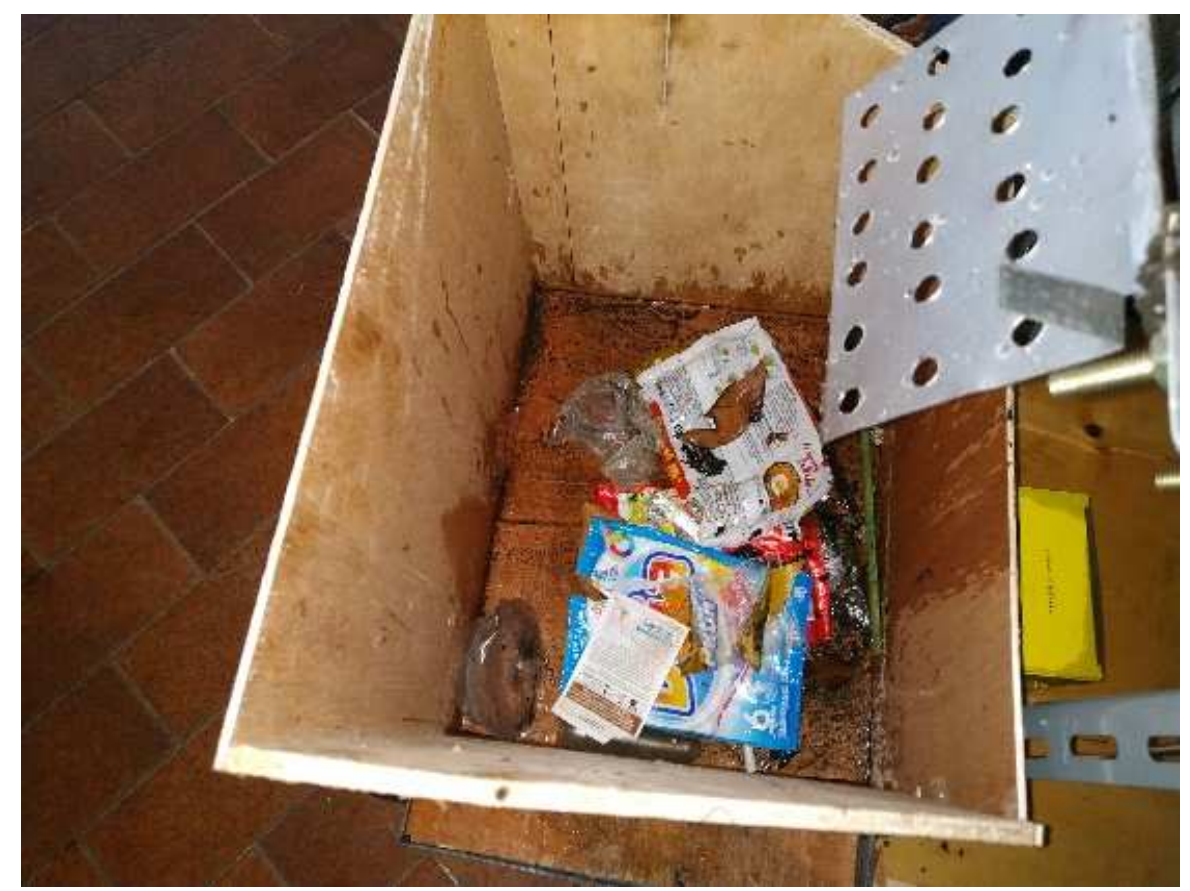

Gambar 9. Hasil pada pengujian pertama 


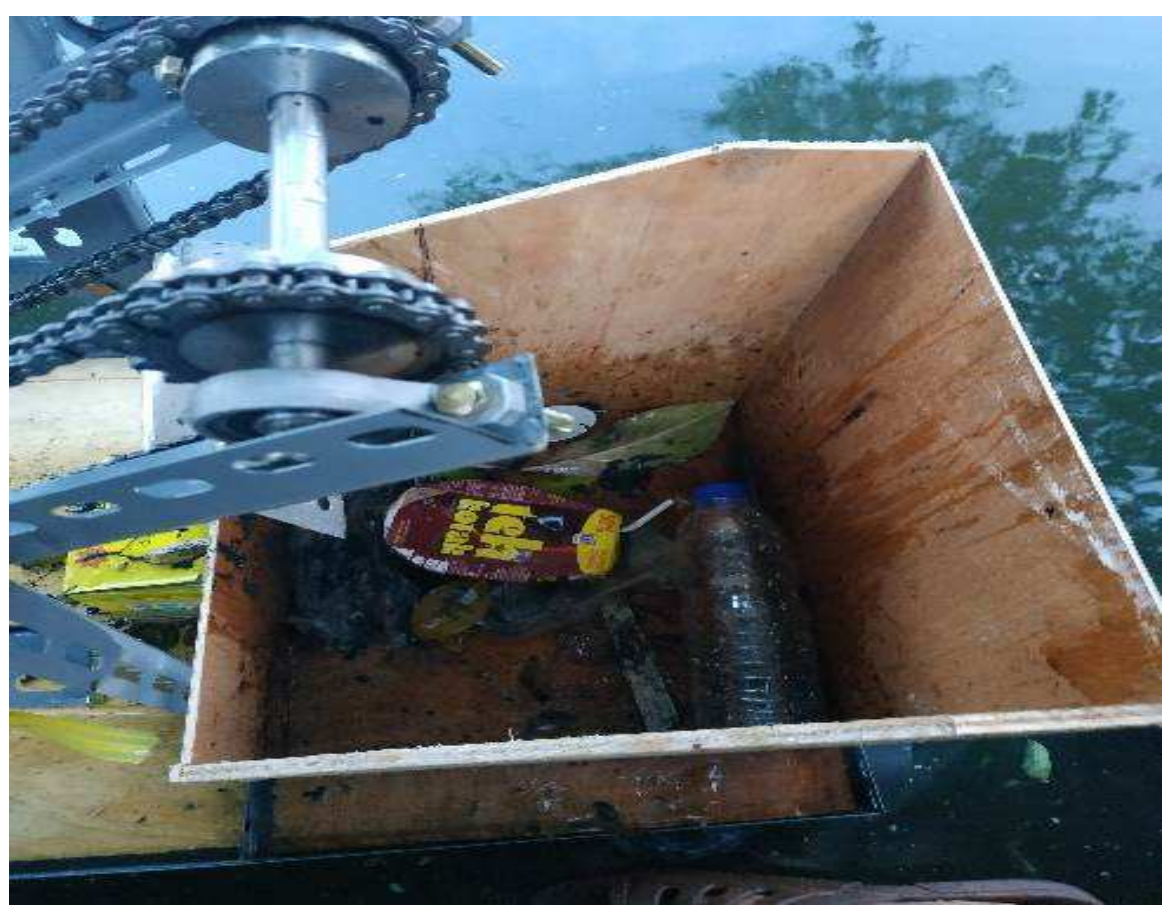

Gambar 10. Hasil pada pengujian kedua

\section{KESIMPULAN}

Kesimpulan dari penelitian ini adalah telah dihasilkan sebuah prototipe Trash Skimmer Boat dengan spesifikasi yang telah dikonsep sebelumnya dengan kemiringan rantai $45^{\circ}$, panjang $100 \mathrm{~cm}$, lebar $40 \mathrm{~cm}$, tinggi $50 \mathrm{~cm}$ dan jumlah bucket sebanyak lima. Trash Skimmer Boat ini membutuhkan kecepatan sebesar $0.46 \mathrm{~m} / \mathrm{s}$ untuk mencapai kapasitas yang ditargetkan yaitu sebesar $5 \mathrm{~kg} / \mathrm{jam}$. Untuk komponen elemen mesin yang digunakan pada trash skimmer boat ini yaitu poros berdiameter $12 \mathrm{~mm}$, bearing dengan diameter bore $12 \mathrm{~mm}$, rantai RS 35 dan sprocket RS 35-1B 20 T. Daya yang dibutuhkan untuk menggerakkan conveyor pada trash skimmer boat ini adalah sebesar 40 watt dan sumber daya yang dihasilkan berasal dari aki 12V 4 AH dan motor penggerak conveyor yang digunakan adalah motor DC 12V 50 RPM. Kapasitas aktual yang berhasil didapatkan oleh Trash Skimmer Boat ini adalah sebesar 200-300 gram dengan waktu pengoperasian selama 30 menit. 


\section{REFERENSI}

[1] K. Data, "Komposisi Sampah di Indonesia Didominasi Sampah Organik," 25 Mei 2019. [Online]. Available: https://databoks.katadata.co.id/datapublish/2019/11/o1/komposisi-sampah-diindonesia-didominasi-sampah-organik.

[2] N. Marliani, PEMANFAATAN LIMBAH RUMAH TANGGA (SAMPAH ANORGANIK) SEBAGAI BENTUK IMPLEMENTASI DARI PENDIDIKAN LINGKUNGAN HIDUP, 2014.

[3] R. Adhiharto dan F. A. Komara, PERANCANGAN KONSTRUKSI TRASH BUCKET CONVEYOR (TBC) SEBAGAI MEKANISME PEMBERSIH SAMPAH SUNGAI, 2016.

[4] A. Fauzi, A. Setiawan dan A. I. Wulandari, "SPECTA Journal of Technology, Vol. 1, No. 1,," PERANCANGAN TRASH SKIMMER BOAT (KAPAL PENGAMBIL SAMPAH) UNTUK KAWASAN SUNGAI KLANDASAN ILIR KOTA BALIKPAPAN, 2019.

[5] N. F. Adiba dan H. A. Kurniawati., Desain Trash Skimmer Amphibi-Boat di Sungai Ciliwung Jakarta, 2016.

[6] A. G. Pramoko dan H. A. Kurniawati., "Jurnal Tugas Akhir Jurusan Teknik Perkapalan FTK ITS," Studi Perancangan Trash-Skimmer Boat di Perairan Teluk Jakarta, 2013.

[7] A. E. Pratama dan H. A. Kurniawati, Desain Aquatic Weed and Trash Skimmer Boat dengan sistem penggerak Paddle Wheel di Sungai Kalimas Surabaya, 2018.

[8] A. J. Zulfikar, "The Flexural Strength of Artificial Laminate Composite Boards made from Banana Stems," Budapest International Research in Exact Sciences (BirEx) Journal, vol. 2, no. 3, pp. 334340, 2020.

[9] G. E. Dieter dan L. C. Schmidt, Engineering Design Fifth Edition, New York: McGraw-Hill, 2013.

[10] S. Ray, INTRODUCTION TO MATERIAL HANDLING, Kolkata: New Age International, 2008.

[11] A. J. Zulfikar, B. Umroh dan M. Y. R. Siahaan, "Design and manufacture of skateboard from banana stem," JMEMME (Journal of Mechanical Enggineering, Manufactures, Materials and Energy), vol. 3, no. 2, pp. 109-116, 2019.

[12] R. Jeffrey, "Technical Information," Roller Drive Chain Selection.

[13] A. J. Zulfikar, A. Sofyan dan M. Y. Siahaan, "Numerical Simulation on The Onion Dryer Frame Capacity of 5 kg/hour," JMEMME (Journal of Mechanical Engineering Manufactures Materials and Energy), vol. 2, no. 2, p. 86-92, 2018.

[14] R. Khurmi dan J. Gupta, Machine Design, New Delhi: Eurasia Publishing House, 2005.

[15] M. Y. Yuhazri, A. J. Zulfikar dan A. Ginting, "Fiber Reinforced Polymer Composite as a Strengthening of Concrete Structures: A Review," dalam 2nd International Conference in Industry and Manufacture Engineerin, Medan, 2020. 